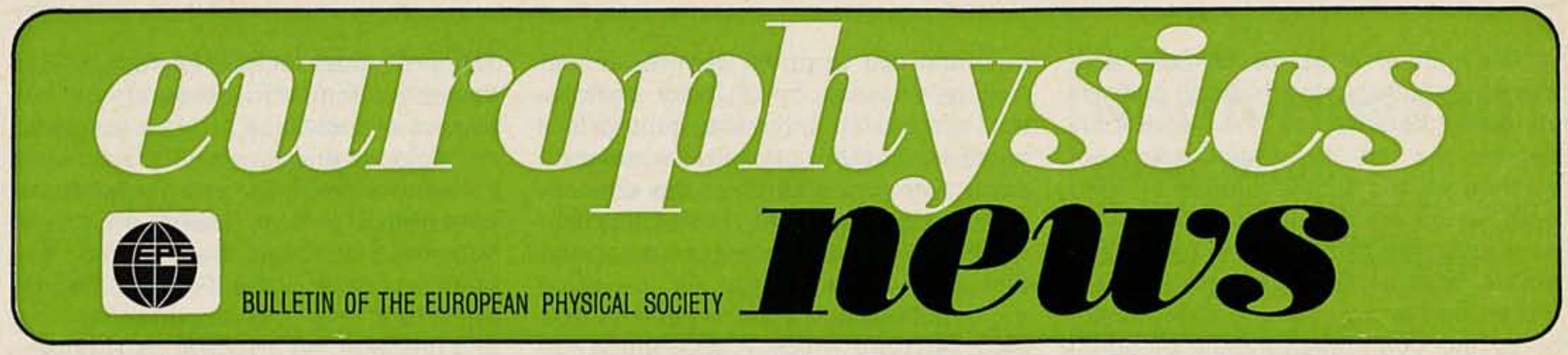

\section{Viewpoint}

\section{A role in the world}

One of the responsibilities of EPS is to ensure representation of the European physics community at international meetings for which physicists, and even national societies, might be ineligible. Whilst such meetings might appear remote from the primarily technical interests of individual physicists, often they arrive at policy decisions which determine the future direction of these interests.

Official Delegates of EPS report on two important meetings in this issue: firstly, D.J. Kroon (Eindhoven, The Netherlands) on the UN Conference on the Human Environment from 5-18 June 1972 ; and, secondly, G. Szigeti (Budapest) on the Unesco Meeting of Experts in Science Policy from European Member States from 4-7 July 1972.

D.J. Kroon outlines how physicists can help to implement the recommendations of the Stockholm Conference on which he reports. G. Szigeti was able to inform the Budapest meeting about the awareness within EPS of the relevance of issues of science policy, and to outline the discussion on this topic at the special session of the EPS Council in Oslo in March 1972 (3 3 (April 1972) 4,6,7). It is significant that, at the Unesco meeting which prepared recommendations on science policy for Ministers in European Member States, EPS was the only scientific society represented.

It is essential that EPS should continue to fulfill its basic purpose of promoting the advancement of physics in Europe and neighbouring countries by attending appropriate highlevel discussions of science policy; in this way, EPS will be playing one of its roles in the world.

\title{
Science in Contemporary Society
}

\section{E. H.S. Burhop}

E.H.S. Burhop, FRS (University College London) represents Individual Ordinary Members on the Council of the European Physical Society ; is President, World Federation of Scientific Workers; and was awarded the Lenin Peace Prize in 1972.

Public attitudes toward science and technology have changed remarkably in recent years. Faced with evident and far reaching evil effects, both real and potential, of some aspects of modern technology, sections of the mass media and even some scientists have come to question the role of science. Despite the facts that $70 \%$ of the people of the world live in abject poverty, with an average income of less than $8 \%$ of that of the $30 \%$ who live in the industrially developed countries, and that they are only likely to raise themselves to a decent standard through the fuller application of science and technology, yet science is represented as a questionable and sometimes even sinister influence. What has led to this dramatic change in public attitudes and what must be done to combat it? These are pro-

\section{Contents}

Viewpoint

Science in contemporary society

Unesco meeting on science policy

UN conference on the human environment

Atomic spectroscopy conference 1

Society news.

Meetings blems to which I believe organizations of scientists should be giving urgent attention. The European Physical Society through its Advisory Committee on Physics and Society has indeed recognised the need for such discussions, but the activities of this Com-mittee should be pursued more vigorously, and should deal with much more fundamental aspects of the problems than they have tackled so far.

There is no doubt that our technological civilization is facing a crisis and that it is related to the economic growth that modern science and technology have made possible.

Last year, six outstanding biologists issued a statement that has become known as the Menton statement and has since been signed by 2100 scientists and public figures in 23 countries. It sets out in concise terms areas in which this crisis confronts us : environmental deterioration; depletion of natural resources; population; overcrowding; and hunger. Estimates of the immediacy of the crisis vary. Paul Ehrlich expects major environmental catastrophes in the 1970s, and some predict chronic deprivation caused by overpopulation by the end of this century. Others predict the real crisis will come somewhat later. Even on the most optimistic forecast, supposing that every square meter of arable land is farmed with the highest yield cereal, Norman Borlaug, architect of the Green Revolution, estimates the maximum number of people that can be fed is $5 \times 10^{10}$. At the present rate of population increase, this number will be reached before the year 2100 .

The Menton statement could have gone on to refer to the area of most immediate crisis of all arising from the continuing and escalating arms race, 
to the nuclear weapons of mass destruction which pose a threat to peoples of every country, to the monstrous perversions of the application of science all too familiar today in Vietnam - the electronic battlefield, millions of acres of defoliated forest and arable land, of land deliberately destroyed by the so-called Rome plough, or by the countless millions of bomb craters that pock-mark the South Vietnamese countryside ensuring that no crops will be raised in these areas in our generation.

There can be no gainsaying that unless action is taken to avert it sometime before the end of this next century, either as a result of devastating nuclear war, or of environmental pollution, or of exhaustion of natural or food resources, mankind faces total catastrophe. Since these crises are all associated in one way or another with the application of science and technology it is little wonder that public attitudes towards our work have changed.

It is even argued that these crises do not arise simply from the way science is applied but are inherent in science itself. Thus " $H$. Marcuse wrote 'When the most abstract achievements of mathematics and physics satisfy so adequately the needs of IBM and the Atomic Energy Commission, it is time to ask whether such applicability is not inherent in the concepts of science itself'. A similar thought has led some young people to question the ethics of studying science at all and to the development of an anti-science cult that has encouraged talented young research workers to opt out of science. This view is wrong and its consequences harmful. Technology may have generated difficult and threatening social and environmental problems but their solution needs more, not less, science and technology. It is not science but the ends its application serves that may be good or evil. Science is neutral, but scientists are not. Many are willing to accept lucrative posts or consultancies without enquiring too closely about the social implications of their work. They are content to leave ethical judgments to others.

\section{Responsibilities of society}

But beyond the scientists is the society within the framework of which they must work. We should not blame science (or scientists) for the sins of society. One could imagine a just society in which the finest ideas of man's intellect and the most beautiful innovations of technique were not used to feed the arms race; in which man scorned to profit from the manufacture of weapons of mass destruction; in which industrial enterprises come to regard disposal of waste products without pollution of the environment as an essential part of the production process, the extra cost being just as much a charge on the price of the finished article as the raw material from which it was made; in which scarce raw materials and energy resources were husbanded with as much care to ensure sufficient were left over for the next years or next generations as a careful housewife budgeting her hard-won housekeeping money; in which population changes were carefully watched and controlled to ensure a balance between food requirements and their supply. All these things would be possible in a society conscious of its responsibilities. They are inconceivable in an acquisitive society in which the accumulation of private wealth, almost irrespective of how it has been obtained, is regarded as a virtue.

\section{Change in public attitudes}

The change in public attitudes towards science has been especially notable in the case of basic science, against which a formidable attack has been mounted from some quarters. As Viktor Weisskopf has put it, we have to face attack from the philistines of the right and of the left. The philistines of the right are interested only in scientific research that shows immediate return in the form of a tidy profit.

\section{Physics and Society- present policy and current prospects}

The Report of the Advisory Committee on Physics and Society was published in the last issue of Europhysics News (3 7 (August 1972) 1-3). It will be discussed during an evening session of the Second EPS General Conference on 3 October 1972.

Full details of the Second EPS General Conference from 3-6 October 1972 in Wiesbaden, Fed. Rep. Germany were also published in the last issue. Anyone who wishes to register should write directly to
U. Dihle
Physikalisches Institut der
Universität
Robert Mayer-Strasse 2-4
D - 6 Frankfurt/Main
Fed. Rep. Germany.

The philistines of the left attack fundamental scientific research on the ground of relevance. I came across an example of this four years ago when I was attending an international conference on high energy physics in Milan. At the time the students had been occupying the Physics Department, but they were courteous to us and allowed us to have our conference in the lecture room. They did request us, however, to allow them to come along to talk to the representatives of the 'international physics community' to discuss some aspects of our work. We readily agreed to meet them one evening after the day's conference programme had concluded. Some of them came to the conference and listened attentively. When they met us in the evening, the spokesman said he had listened to us discussing an experiment in which we proposed to examine some 40,000 examples of the interactions of neutrinos with nucleons. He asked what was the relevance of such work? Did we realize that this was about the number of people dying each day throughout the world owing to effects of malnutrition and hunger? Would not our time and talents be better occupied dealing with more relevant problems? We tried to explain that the experiments we were planning were aimed at learning something new about very basic properties of matter, right on the far frontiers of our knowledge; that these experiments could decide whether even the nucleon was a fundamental particle or whether it had a granular structure; that the investigation of matter at this level had the same kind of intrinsic interest as the discovery of pulsars or quasars in astronomy. I don't think we convinced these revolutionary students.

\section{Cultural value of science}

We have tended to take for granted that the study of nature, the solution of the most challenging problems of the fundamental nature of matter and its basic interactions, and how particles and interactions can account for the phenomena we observe around us or in the other parts of the universe, were good and desirable things - a part of our culture. But now the philistines of the right are saying that this is all a waste of time and money. We must turn our attention to the most pedestrian 'applied' problems showing an immediate economic return.

Science is part of our culture and part of its justification must follow the same lines as the considerations we use for justifying the subsidizing 
of our opera houses, concert halls, and sports stadia. The difficulty is of course that basic science in the most exciting fields of high energy physics and the various kinds of astronomy is very expensive. In the 1930's when J.D. Bernal wrote his Social Function of Science, the total sum spent on research and development in Britain amounted to about $£ 6 \mathrm{M}$, about $0.1 \%$ of the gross national product (GNP). Today about $0.1 \%$ of the greatly increased GNP of $£ 30,000 \mathrm{M}$ is devoted to basic research in just the one field of high energy physics in Britain. I am sure the decision to finance this field of research on this scale is far-sighted and justified by its great interest. One cannot work in this field without costly accelerators and other apparatus, so that the choice is between large expenditure or not studying the subject at all. There is no middle way. Much is given to high energy physicists, and they should realize that this, in turn, imposes a responsibility on them.

Unfortunately, however, although increasing numbers of people in the community are able to enjoy the culture offered by the theatre, opera or concert hall, the numbers able to appreciate the importance of discoveries in high energy physics are counted in hundreds. This is really a reflection of the science consciousness of ordinary people in most western societies. The educational system has not succeeded in presenting science as part of the general culture.

\section{Trends in Physics}

\begin{abstract}
Volume of Plenary Lectures given at the Second EPS General Conference, Wiesbaden, Federal Rep. Germany, 3-6 October 1972.
\end{abstract}

This publication will be available early in 1973 for Sw. Frs. 55.(including postage).

Individual Ordinary Members of EPS may purchase it for Sw. Frs. 50.- (including postage). from

Please order your copy now

European Physical Society, Trends in Physics, P.O. Box 39, CH-1213 Petit-Lancy 2, Switzerland.
Our university courses mainly concentrate on training specialized professional scientists but have given little attention even to inter-disciplinary science courses for scientists, and almost none at all to general courses for students of the humanities.

\section{Social responsibility of scientists}

Research scientists themselves have a duty to give attention to the problem of explaining to non-scientists both what they are attempting to do and why they are doing it. The ideas in a field like elementary particle physics may be difficult and subtle. The manner in which they can be presented to a popular audience requires a good deal of thought. Success in explaining ideas on the popular level depends to a considerable extent on how thoroughly one really understands them oneself. Nevertheless scientists who require the public to contribute considerable sums for their research have a responsibility to render an account to the public of their achievements.

The public image of science and scientists is largely related to the tasks required of science and reflects the general malaise of our society. But scientists can help to change the public image of science by showing concern for the way their work is used, and by accepting their responsibility to present its meaning and implications in terms the public can understand.

Fortunately there seems to be, among scientists, a growing sense of social responsibility. In many countries, this has led to the formation of national societies for social responsibility in science. The World Federation of Scientific Workers, which has affiliates in 30 countries representing 300,000 qualified scientists, has striven for 25 years to further the ideas of social responsibility, international scientific co-operation, the proper application of science for development, for effective disarmament and the abolition of weapons of mass destruction. Aims such as these in which scientists are seen to be concerned with the use made of their work can perhaps help to refurbish the somewhat tarnished public image of science.

In pursuit of such objectives there is room for co-operation between the Physics and Society Committee of the European Physical Society, the similar section of the American Physical Society, the World Federation of Scientific Workers, national societies for Social Responsibility in Science, the Pugwash Movement, and other bodies of scientists with similar aims.
A new North-Holland publication

General Editor : L. Rosenfeld Professor at the Nordic Institute for Theoretical Atomic Physics, Copenhagen.

\section{NIELS BOHR}

\section{COLLECTED WORKS}

Volume I : Early Work 1905-1911

Edited by J. Rud Nielsen

George Lynn Cross Research Professor Emeritus, University of Oklahoma.

1972. 656 pages. Dfl. 180,00 (ca. $\$ 56.25$ ) ISBN 0720418011.

Subscription price : Dfl. 150 (ca. \$48.50)

This is the first volume of a comprehensive, critical edition of Niels Bohr's work. Besides his published papers, it includes unpublished manuscripts and a wide selection of letters and other documents, with explanatory introductions and notes by the Editor of each volume.

It will provide historians of science with a serviceable tool for the study of Bohr's great creative work in atomic and nuclear physics, and of his contributions to epistemology.

\section{CONTENTS}

\section{General Introduction}

Niels Bohr: Biographical Sketch

Part I: Surface Tension of Water. Introduction. Curves pertaining to surface tension (1905-06?). Prize essay in Physics for 1905. First Royal Society Paper. Addendum to prize essay. Second Royal Society Paper.

Part II : Electron Theory of Metals. Introduction. M.Sc. examination paper. The doctor's dissertation. Correspondence about the dissertation (1911). Lecture on the electron theory of metals. Letters to Oseen and to McLaren (December 1911). Note concerning a paper by J. Stark (1912). Note on the electron theory of thermoelectric phenomena (1912). Lectures on the electron theory of metals held in the University of Copenhagen in the spring of 1914. Correspondence with G.H. Livens (1915). Correspondence with O.W. Richardson (1915).

Part III : Selected family correspondence 1909-1916. Introduction. Original texts. Translations. Inventory of family correspondence in the Niels Bohr Archive.

Inventory of Manuscripts in the Niels Bohr Archive. Documents related to surface tension and

Index. the electron theory of metals.

\section{NORTH HOLLAND}

P.O. Box 1270 - Amsterdam - The Netherlands Sole distributors for the U.S.A. and Canada: American Elsevier Publishing Company, Inc., 52 Vanderbilt Avenue, New York - N.Y. 10017. 